\title{
Metabolically healthy obese and metabolic syndrome of the lean: the importance of diet quality. Analysis of MAGNETIC cohort
}

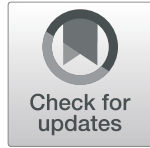

Kamila Osadnik ${ }^{1}$,Tadeusz Osadnik ${ }^{1,2^{*}}$ (D), Marta Lonnie ${ }^{3}$, Mateusz Lejawa ${ }^{1}$, Rafał Reguła ${ }^{4}$, Martyna Fronczek ${ }^{5}$, Marcin Gawlita ${ }^{5,6}$, Lidia Wądołowska ${ }^{3}$, Mariusz Gąsior ${ }^{4}$ and Natalia Pawlas ${ }^{1}$

\begin{abstract}
Background: Obesity is considered as an indispensable component of metabolic health assessment and metabolic syndrome diagnosis. The associations between diet quality and metabolic health in lean, young adults have not been yet established whilst data addressing this issue in overweight and obese subjects is scarce. Our analysis aimed to establish the link between diet quality (measured with data-driven dietary patterns and diet quality scores) and metabolic syndrome (MS) in young adults, regardless of their adiposity status.
\end{abstract}

Methods: A total of 797 participants aged 18-35 years old were included in the study. Participants were assigned into metabolic syndrome (MS) group if at least two abnormalities within the following parameters were present: blood pressure, triglycerides, total cholesterol, HDL cholesterol, blood glucose. Participants with one or none abnormalities were considered as metabolically healthy subjects $(\mathrm{MH})$, Diet quality was assessed with two approaches: 1) a posteriori by drawing dietary patterns (DPs) with principal component analysis (PCA) and 2) a priori by establishing diet quality scores and the adherence to pro-Healthy-Diet-Index (pHDI) and non-Healthy-DietIndex (nHDI). Logistic regression with backward selection based on Akaike information criterion was carried out, to identify factors independently associated with metabolic health.

Results: Within the MS group, 31\% were of normal weight. Three PCA-driven DPs were identified, in total explaining 30.0\% of the variance: "Western" (11.8\%), "Prudent" (11.2\%) and "Dairy, breakfast cereals \& treats" (7.0\%). In the multivariate models which included PCA-driven DPs, higher adherence to middle and upper tertiles of "Western" DP (Odds Ratios [OR] and 95\% Confidence Intervals [95\% Cl]: 1.72, 1.07-2.79 and 1.74, 1.07-2.84, respectively), was associated with MS independently of clinical characteristics including BMI and waist-hip ratio (WHR). Similar results were obtained in the multivariate model with diet quality scores - MS was independently associated with higher scores within $\mathrm{nHDI}(2.2,0.92-5.28)$.

Conclusions: Individuals with MS were more likely to adhere to the western dietary pattern and have a poor diet quality in comparison to metabolically healthy peers, independently of BMI and WHR. It may imply that diet composition, as independent factor, plays a pivotal role in increasing metabolic risk. Professional dietary advice should be offered to all metabolically unhealthy patients, regardless of their body mass status.

Keywords: Dietary patterns, Diet quality, Metabolic health, Metabolic syndrome, Principal component analysis, Young adults

\footnotetext{
* Correspondence: tadeusz.osadnik@sccs.pl

${ }^{1}$ Department of Pharmacology, Faculty of Medical Sciences in Zabrze,

Medical University of Silesia, Jordana 38, 41-808 Zabrze, Poland

${ }^{2} 2$ nd Department of Cardiology and Angiology, Silesian Center for Heart

Diseases, Marii Skłodowskiej-Curie 9, 41-800 Zabrze, Poland

Full list of author information is available at the end of the article
}

C The Author(s). 2020 Open Access This article is distributed under the terms of the Creative Commons Attribution 4.0 International License (http://creativecommons.org/licenses/by/4.0/), which permits unrestricted use, distribution, and reproduction in any medium, provided you give appropriate credit to the original author(s) and the source, provide a link to the Creative Commons license, and indicate if changes were made. The Creative Commons Public Domain Dedication waiver (http://creativecommons.org/publicdomain/zero/1.0/) applies to the data made available in this article, unless otherwise stated. 


\section{Introduction}

Despite historical disparities in defining metabolic syndrome (MS), the commonly accepted description is the occurrence of obesity, clustered with two or more metabolic abnormalities such as hypertriglyceridemia, reduced high-density cholesterol (HDL), raised blood pressure and/or elevated fasting blood glucose levels [1]. However, the necessity of the obesity criterion in the metabolic health assessment has lately raised controversies. In the Italian cohort, Buscemi et al. [2] observed, that while $27.4 \%$ of the overweight-obese participants were metabolically healthy, $36.7 \%$ of the normal-weight participants were metabolically unhealthy. Therefore, along with the concept of metabolically healthy obese, a concept of the lean MS has emerged [3-5]. To date, many authors attempted to describe the problem, referring to this specific subpopulation as 'normal weight obese' [6], 'metabolically obese nonobese' [7], 'thin on the outside fat on the inside - TOFI' [8], or 'metabolically unhealthy normal weight' [9]. The phenomenon is being explained by the excessive and metabolically active visceral adipose tissue (VAT) [10]. The VAT is not always reflected in the BMI or waist circumference parameters, which remain within normal ranges [6-9]. Hence, the assessment of abdominal obesity based on the most commonly used measures has been identified as a serious 'missing risk' in patients' diagnosis [8]. Furthermore, recent studies have shown, that patients with MS are at higher risk of developing diabetes [5], coronary heart disease [11] or stroke [12], as compared to their metabolically healthy obese counterparts. In contrary, the obese, but metabolically healthy patients are at lower risk of developing heart disease or diabetes than lean or overweight subjects with at least two mentioned abnormalities [5, 13].

High prevalence of MS in lean patients and a relatively high percentage of metabolically healthy patients in the obese population suggests that apart from overall caloric load, diet quality might be one of the independent predictors of metabolic health [14-17]. Diet is one of the major modifiable risk factor contributing to the development of chronic diseases [18]. Particularly detrimental pattern linked to MS is being described as the 'western' pattern; defined by a high intake of red and processed meats, fast foods, refined grains, desserts, sweets [19]. The latter relationship is well documented in multiple studies [20-22] and confirmed in the recently published meta-analyses by Rodríguez-Monforte et al. [23] and Shab-Bidar et al. [24]. To our knowledge, no previous studies used two different approaches in assessing diet quality in the context of metabolic health in a group of young adults.

Our analysis aimed to establish the link between diet quality (measured with data-driven dietary patterns and diet quality scores) and MS in young adults, regardless of their adiposity status.

\section{Methods \\ Ethical approval}

The study was conducted following the Declaration of Helsinki and good clinical practice. The study protocol has been approved by the Ethics Committee at the Institute of Occupational Medicine and Environmental Health, Sosnowiec and Medical University of Silesia. Informed written consent was obtained from all subjects enrolled in the study.

\section{Study sample and recruitment}

Participants in this study were subjects from the MAGNETIC (Metabolic and Genetic Profiling of Young Adults with and without a Family History of Premature Coronary Heart Disease) study. The design and methodology of the study have been described previously [25, 26]. For the purpose of the current study, the sample was recruited between July 2015 and December 2017 (Fig. 1).

Since the primary aim of the MAGNETIC project was to analyse classical, genetic and metabolic risk factors of coronary artery disease (CAD) in healthy young adults with and without a family history of premature coronary artery disease (P-CAD), the inclusion criteria were: age $\geq$ 18 and $\leq 35$ years old, angiographically documented PCAD in first-degree relatives (cases) or no P-CAD in first-degree relatives (control group). The exclusion criteria were: age $<18$ or $>35$ years, failure to provide informed consent, pregnancy, lactation and acute or chronic diseases requiring pharmacotherapy. Subjects with a positive family history of P-CAD were recruited among young healthy patients of Silesian Centre for Heart Disease, and through contacting offspring of older patients hospitalized in 2010-2017 due to P-CAD. The control group was recruited from healthy subjects aged 18-35 years, who attended screening appointment at the centre.

\section{Metabolic health}

Resting blood pressure was measured in a sitting position with the use of an automated blood pressure monitor. Fasting plasma glucose, and serum levels of total cholesterol, HDL cholesterol and triglycerides were obtained after requested $12 \mathrm{~h}$ fast. Next, based on the metabolic health criteria proposed by Buscemi et al. [2], the sample was divided into two distinct groups: metabolically healthy subjects - individuals without MS and subjects with MS (Table 1). Anthropometric measurements (height, weight, and waist circumference) were obtained during the first appointment at Silesian Centre for Heart Disease. Body mass index (BMI) was calculated 


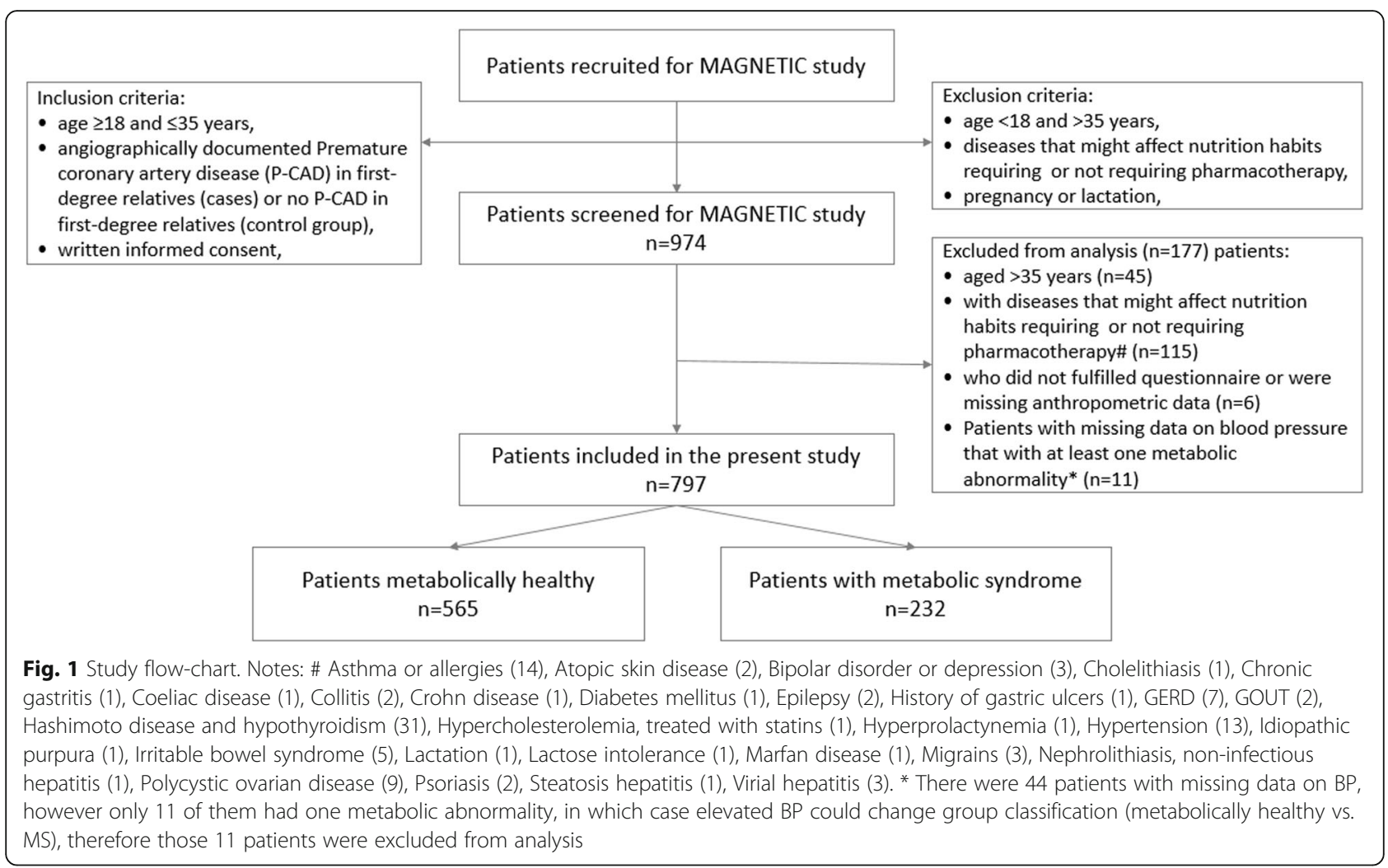

to assess general adiposity. To classify participants as normal weight and overweight or obese within the $\mathrm{MH}$ and MS groups, BMI was used as categorical variable, in accordance to WHO cut-offs point: normal weight (18.5 to $24.99 \mathrm{~kg} / \mathrm{m} 2$ ), overweight ( 25 to $29.99 \mathrm{~kg} / \mathrm{m} 2$ ) and obese $(\geq 30 \mathrm{~kg} / \mathrm{m} 2)$ [27]. Waist-Hip Ratio (WHR) was calculated to assess central fat distribution. WHR and

Table 1 Definition of metabolic health [2]

\begin{tabular}{|c|c|}
\hline Parameter & Cut-offs \\
\hline \multirow[t]{2}{*}{ Blood pressure } & $\mathrm{SBP} \geq 130 \mathrm{mmHg}$ or $\mathrm{DBP} \geq 85 \mathrm{mmHg}$ \\
\hline & $\begin{array}{l}\text { or use of antihypertensive } \\
\text { medication }^{\mathrm{a}}\end{array}$ \\
\hline \multirow[t]{2}{*}{ Triglycerides } & $\geq 150 \mathrm{mg} / \mathrm{dl}$ \\
\hline & or use of lipid-lowering medication ${ }^{a}$ \\
\hline \multirow[t]{2}{*}{ HDL cholesterol } & Men < 40 mg/dl $(1.0 \mathrm{mmol} / \mathrm{l})$ \\
\hline & Women < $50 \mathrm{mg} / \mathrm{dl}(1.2 \mathrm{mmol} / \mathrm{l})$ \\
\hline \multirow[t]{2}{*}{ Total cholesterol } & $>200 \mathrm{mg} / \mathrm{dl}(5.2 \mathrm{mmol} / \mathrm{l})$ \\
\hline & $\begin{array}{l}\text { or use of cholesterol-lowering } \\
\text { medication }^{\mathrm{a}}\end{array}$ \\
\hline Glucose & $\begin{array}{l}\text { Glucose }>100 \mathrm{mg} / \mathrm{dl}(>5.55 \mathrm{mmol} / \mathrm{l}) \\
\text { or diabetes mellitus type } 2\end{array}$ \\
\hline $\begin{array}{l}\text { Metabolically healthy } \\
\text { (without metabolic syndrome) }\end{array}$ & $0-1$ of the above cut-offs \\
\hline $\begin{array}{l}\text { Metabolically unhealthy } \\
\text { (with metabolic syndrome) }\end{array}$ & $\geq 2$ of the above cut-offs \\
\hline
\end{tabular}

WC were used as continuous variables and interpreted as follows: the higher value, the greater proportion of abdominal fat.

\section{Diet quality}

Considering that human diet is a cluster of various dietary behaviours, two approaches have been adopted to investigate the associations between diet and metabolic abnormalities: a priori determined with diet quality scores and a posteriori as the adherence to data-driven dietary patterns, which represent the overall diet of studied populations [28].

Two validated food frequency questionnaires were used to assess diet quality. For data-driven dietary pattern analysis (a posteriori approach), data was collected using validated for Polish population food frequency questionnaire (FFQ-6) [29]; the self-administered version of FFQ-6 was used. The questionnaire was previously used in various populations [30-32], with the reproducibility being recently described in detail elsewhere [29]. To analyse diet quality expressed in scores (a priori approach), dietary data was collected using KomPAN questionnaire [33, 34]. Detailed description regarding reproducibility and validity of the questionnaire has been previously described [34]. Enrolled participants received questionnaires from trained researches, who provided guidance and assistance as required, on the one-to-one basis. Questionnaires were completed and returned 
along with signed informed consents, prior to further data collection.

\section{Dietary data for PCA-driven dietary patterns}

FFQ-6 includes a comprehensive variety of foods (62 food items) usually consumed in Poland [29]. For the purpose of this study 46 food items were considered including 'fruit in total' and 'vegetables in total', and excluding single fruit and vegetable items. Participants could choose one of six categories, ranging from 'never or very rarely' to 'few times a day'. The frequencies of consumption were converted into numerical values and expressed as times/day as follows: 'never or very rarely' = 0 ; 'once a month or less' $=0.025$; 'several times a month' $=0.1$; 'several times a week' $=0.571$; 'daily' $=1$; 'few times a day' $=2$ [29]. Some of the food items were further combined by summing their daily frequency consumption (times/day). In total, 26 foods or food groups were included in the multicomponent analysis to identify dietary patterns (Additional file 1: Table S1).

\section{Dietary data for diet quality scores}

Diet quality scores were calculated according to manual of KomPAN questionnaire based on the usual food frequency consumption of 24 food items over the past year [33, 34]. Participants could choose one of six categories: never, 1-3 times a month, once a week, a few times a week, once a day or few times a day. The frequencies were converted into daily frequency (times/day) with numerical values assigned as follows: $0,0.06,0.14,0.5,1$ and 2, respectively. Next, two diet quality scores were used: pro-Healthy-Diet-Index (pHDI) and non-HealthyDiet-Index (nHDI). The pHDI included 10 food items: wholemeal bread/bread rolls, coarse-ground groats, milk, fermented milk drinks, cheese curd products, white meat, fish, legumes, fruit and vegetables. The nHDI included 14 food items: white bread and bakery products, white rice and fine-ground groats, fast foods, fried foods, butter, lard, cheese, cured meat/smoked sausages/hotdogs, red meat, sweets, tinned meats, sweetened carbonated or still drinks, energy drinks, alcoholic beverages (Additional file 1: Table S2). Daily frequencies of the consumption of the selected food items (10 items for pHDI and 14 items for nHDI) were summed up and recalculated into ranges from 0 to $100 \%$ points according to questionnaire's manual $[33,34]$.

\section{Other factors}

\section{Sociodemographic}

Data regarding sociodemographic variables were obtained using KomPAN questionnaire, described earlier ("Diet quality" section) [33]. Age (in years) and sex were recorded. Place of residence, level of education, financial situation collected using closed structured questions.
Next, based on respondents' declarations, dichotomous categories were created as follows: place of residence (village/city $<20,000$ inhabitants vs. city $>20,000$ inhabitants), education (higher vs primary/lower secondary or secondary), financial situation (average/below average vs. above average) [33].

\section{Lifestyle}

Data regarding lifestyle variables were collected with KomPAN questionnaire and included: physical activity at leisure time, smoking and smoking status [33]. Physical activity at leisure time was assigned using three categories based on intensity: low (sitting, screen time, reading, light housework, walking less than $2 \mathrm{~h}$ a week), moderate (walking, cycling, moderate exercise, working at home or other light physical activity performed 2-3 $\mathrm{h} /$ week) or high (cycling, running, working at home or other sports activities requiring physical effort over $3 \mathrm{~h} /$ week). Then, dichotomous categories for the purpose of multivariable analyses were created as follows: physical activity at leisure time (low or moderate vs. high), smoking (non-smoker or past smoker vs. current smoker).

\section{Family history}

Family history of diabetes in 1st and 2nd degree relative(s) was investigated during medical interviews during the first appointment at the centre. P-CAD in 1st degree relative(s) was confirmed angiographically.

\section{Nutrition knowledge}

Nutrition knowledge was assessed using KomPAN questionnaire [33]. Participants' had to provide answers (true/false/unsure) to the set of 25 statements; 1 point was or assigned for every correct answer, and 0 points for the wrong answer or "unsure". Next, all points were summarized to express nutrition knowledge score in points.

\section{Statistical analysis}

Data was presented as sample percentages (\%) and means with standard deviations (SDs) for variables with a normal distribution (e.g. regarding metabolic health) or medians with interquartile range (IQR) for variables without normal distribution (e.g. regarding food frequency consumption). Differences between groups were verified with Student's t-test for means or MannWhitney-U test for medians or chi-square test for percentage distribution.

Principal component analysis (PCA) was used to derive PCA-driven dietary patterns. To derive dietary patterns (DPs), the frequency of consumption of 26 food groups (times/day) was standardized so that values had a mean of 0 and a standard deviation of 1. PCA with promax rotation was used. Components to retain were 
based on their interpretability and eigenvalues $(>1)$ and a break-point identified in the Scree test. The contribution of each questionnaire item to each DP is reflected by the item's factor loading. Factor loadings $>|0.30|$ were considered to be of significant contribution to identified DPs. Dietary patterns were labelled according to variables with the highest loadings for each dietary pattern. For each subject, a DP score that reflects adherence to the DP was calculated (as a sum of the product of the food frequency consumption and factor loading for 26 food groups). Based on tertile distribution, for each DP subjects were divided into three groups: bottom, middle and upper tertile and interpreted as lowest, moderate and highest adherence to the DP, respectively.

Unconditional logistic regression analysis was used to assess the association between metabolic health status and adherence to identified DP or diet quality scores [35]. Univariate and multivariate logistic regression with backward selection models were carried out, to identify factors independently associated with metabolic health status. Factors that were kept in the multivariate model were based on the Akaike information criterion. Variables that were initially included in model were as continuous variables: age, BMI, WHR, and as categorical variables: sex, place of residence, financial situation, education, smoking status, physical activity at leisure time, family history of diabetes mellitus in 1st and 2nd degree relative(s), family history of P-CAD in 1st degree relative(s) as well as PCA-driven DPs (categorical variables) and diet quality scores (continuous variables). Two separate multivariate models were built for tertile intervals of each DP calculated for dietary pattern scores, and for models incorporating pHDI and nHDI (both in \% points).

There was a total of $0.8 \%$ of missing values. Before performing multivariable logistic regression analysis missing values were imputed using the missForest data imputation algorithm. For all tests, the $P$-value of $<0.05$ was considered to be statistically significant.

\section{Results}

\section{Sample characteristics}

In comparison to the $\mathrm{MH}$ group, the MS group had a higher mean BMI $(23.0 \pm 3.5$ vs. $27.8 \pm 4.6 \mathrm{~kg} / \mathrm{m} 2$, respectively), WHR $(0.82 \pm 0.09$ vs. $0.90 \pm 0.08$, respectively) and WC $(85.1 \pm 9.0$ vs. $92.9 \pm 11.6$ and $72.2 \pm 9.0$ vs. $89.3 \pm 14.8$, for men and women respectively) (Table 2). Within the MH group, approx. $73 \%$ of the subjects were normal weight and approx. $27 \%$ were overweight or obese. Within the MS group, approx. $31 \%$ of subjects were normal weight and $69 \%$ were overweight or obese. Patients from the MS group were older $(29.4 \pm$ 4.1 vs. $27.2 \pm 4.5$ years), more often males. A higher percentage of patients with a family history of P-CAD was found in the MS then MH group (57.8\% vs. 46.0\%). Also, the nutrition knowledge was lower in the MS group, in comparison to the $\mathrm{MH}$ group $(11.5 \pm 4.0$ vs. $12.5 \pm 3.9$ points, respectively). There were no differences between $\mathrm{MH}$ and MS subjects with regards to the place of residence, education level, financial situation, nutrition knowledge score, physical activity level, smoking status, family history of diabetes mellitus. Blood pressure, glucose and lipid parameters were significantly different between the groups (Table 2).

\section{Diet quality}

\section{PCA-driven dietary patterns}

The principal component analysis identified three dietary patterns in total explaining $30.0 \%$ of the variance (Table 3). "Western" dietary pattern was characterised by higher consumption frequency of processed meat (0.70), potatoes $(0.62)$, refined grain products $(0.56)$, animal fats $(0.54)$, red meats (0.53), other edible fats (0.45), sweetened beverages and energy drinks (0.40), sugar (0.39), alcohol (0.36), cheeses (0.35) and sweets and snacks (0.35), white meat (0.30). "Prudent" dietary pattern was characterised by higher frequency consumption of wholegrain products (0.64), vegetables (0.62) fish (0.53), eggs and egg dishes (0.52), nuts and seeds (0.52), fruits (0.51), milk, fermented milk drinks and curd cheese (0.44), vegetable oils (0.41), white meat (0.39) and legumes $(0.38)$. The third dietary pattern, "Dairy breakfast cereals \& treats" was characterized by frequent consumption of sweetened milk products (0.70), milk, fermented milk drinks and curd cheese (0.54), breakfast cereals $(0.49)$, sweets and snacks $(0,47)$ and fruit (0.43) (Table 3).

\section{Diet quality scores}

Medians and interquartile ranges of frequency consumptions of food items within pHDI and nHDI are listed in Table 4. In total, the median of pHDI was 6.84 times/ day (within the range $0-20$ ) and median of nHDI was 4.70 times/day (within the range $0-28$ ).

\section{Associations between diet and metabolic health}

In the univariate analysis, higher adherence to nHDI (Odds Ratio: 4.28 per 10\% points increase, 95\% Confidence Interval: 2.16-8.58) and higher adherence to "Western" DP (highest vs. lowest adherence: 2.28, 1.553.39; moderate vs. lowest adherence: 1.82, 1.23-2.72) was associated with MS. Other significant factors associated with MS in this model included: male gender (5.32, 3.67-7.85), WHR (2.9 per 0.1 unit increase, 2.363.6), P-CAD in 1st degree relative(s) (vs. no P-CAD: 1.6, 1.19-2.18), high physical activity (vs. low and moderate: $1.45,1.03-2.03$ ), current smoking (vs. past and never smoking: $1.41,0.99-2.01)$, BMI (1.34 per $1 \mathrm{~kg} / \mathrm{m} 2$ increase, $1.27-1.4)$, age (1.12 per 1 year increase, 1.08 
Table 2 Characteristics of study participants by metabolic health status (number (\%) or mean \pm standard deviation or median \pm interquartile range)

\begin{tabular}{|c|c|c|c|c|}
\hline Variables & Total sample & $\mathrm{MH}$ & MS & $P$ value \\
\hline Sample size & 797 & 565 & 232 & - \\
\hline Sample percentage & 100 & 70.9 & 29.1 & - \\
\hline \multicolumn{5}{|l|}{ Sociodemographic } \\
\hline Age (years) & $27.9 \pm 4.5$ & $27.2 \pm 4.5$ & $29.4 \pm 4.1$ & $<0.0001$ \\
\hline Male sex (\%) & $460(57.7)$ & $268(47.4)$ & $192(82.8)$ & $<0.0001$ \\
\hline \multicolumn{5}{|l|}{ Residence (\%) } \\
\hline village & $121(15.2)$ & $80(14.2)$ & $41(17.7)$ & \multirow{4}{*}{0.179} \\
\hline small town $(<20,000$ inhabitants $)$ & $89(11.2)$ & $68(12.0)$ & $21(9.1)$ & \\
\hline town (20,000 to 100,000 inhabitants) & $161(20.2)$ & $107(18.9)$ & $54(23.3)$ & \\
\hline city (> 100,000 inhabitants) & $426(53.5)$ & $310(54.9)$ & $116(50.0)$ & \\
\hline \multicolumn{5}{|l|}{ Education (\%) } \\
\hline primary/lower secondary & $53(6.6)$ & $29(5.1)$ & $24(10.3)$ & \\
\hline upper secondary & $302(37.9)$ & $213(37.7)$ & $89(38.4)$ & \multirow[t]{2}{*}{0.021} \\
\hline higher & $442(55.5)$ & $323(57.2)$ & $119(51.3)$ & \\
\hline \multicolumn{5}{|l|}{ Financial situation } \\
\hline average/below average & $598(75.1)$ & $431(76.4)$ & $167(72.0)$ & \multirow{2}{*}{0.05} \\
\hline above average & $198(24.9)$ & $133(23.6)$ & $65(28.0)$ & \\
\hline Nutrition knowledge score (points) & $12.2 \pm 3.9$ & $12.5 \pm 3.9$ & $11.5 \pm 4.0$ & 0.0009 \\
\hline \multicolumn{5}{|l|}{ Lifestyle } \\
\hline \multicolumn{5}{|l|}{ Physical activity at leisure } \\
\hline low & $206(25.8)$ & $134(23.7)$ & $72(31.0)$ & \\
\hline moderate & $366(45.9)$ & $264(46.7)$ & $102(44.0)$ & 0.087 \\
\hline high & $225(28.2)$ & $167(29.6)$ & $58(25.0)$ & \\
\hline Current smoking (vs. non-smoking) (\%) & $184(23.3)$ & $120(21.4)$ & $64(27.8)$ & 0.053 \\
\hline \multicolumn{5}{|l|}{ Family health history } \\
\hline Diabetes mellitus in 1st degree relatives (\%) & $113(14.2)$ & $73(12.9)$ & $40(17.2)$ & 0.112 \\
\hline Premature CAD in 1st degree relatives (\%) & $394(49.4)$ & $260(46.0)$ & $134(57.8)$ & 0.003 \\
\hline \multicolumn{5}{|l|}{ Dietary } \\
\hline pHDI (\% points) & $21.0 \pm 10.1$ & $21.6 \pm 9.9$ & $19.7 \pm 10.6$ & 0.005 \\
\hline nHDI (\% points) & $17.5 \pm 8.1$ & $16.7 \pm 7.8$ & $19.4 \pm 8.3$ & $<0.0001$ \\
\hline \multicolumn{5}{|l|}{ Lowest adherence to DP (\%) } \\
\hline Prudent & $266(33.4)$ & $179(31.7)$ & $87(37.5)$ & 0.113 \\
\hline Western & $266(33.4)$ & $213(37.7)$ & $53(22.8)$ & $<0.0001$ \\
\hline Dairy, breakfast cereals \& treats & $266(33.4)$ & $176(31.2)$ & $90(38.8)$ & 0.809 \\
\hline \multicolumn{5}{|l|}{ Moderate adherence to DP (\%) } \\
\hline Prudent & $266(33.4)$ & $196(34.7)$ & $70(30.2)$ & 0.219 \\
\hline Western & $266(33.4)$ & $183(32.4)$ & $83(35.8)$ & 0.357 \\
\hline Dairy, breakfast cereals \& treats & $266(33.4)$ & $196(34.7)$ & $70(30.2)$ & 0.219 \\
\hline \multicolumn{5}{|l|}{ Highest adherence to DP (\%) } \\
\hline Prudent & $265(33.2)$ & 190 (33.6) & $75(32.3)$ & 0.7233 \\
\hline Western & $265(33.2)$ & $169(29.9)$ & $96(41.4)$ & 0.002 \\
\hline Dairy, breakfast cereals \& treats & $265(33.2)$ & $193(34.2)$ & $72(31.1)$ & 0.395 \\
\hline
\end{tabular}


Table 2 Characteristics of study participants by metabolic health status (number (\%) or mean \pm standard deviation or median \pm interquartile range) (Continued)

\begin{tabular}{|c|c|c|c|c|}
\hline Variables & Total sample & $\mathrm{MH}$ & MS & $P$ value \\
\hline \multicolumn{5}{|l|}{ Adiposity } \\
\hline BMI $\left(\mathrm{kg} / \mathrm{m}^{2}\right)$ & $24.4 \pm 4.4$ & $23.0 \pm 3.5$ & $27.8 \pm 4.6$ & $<0.0001$ \\
\hline \multicolumn{5}{|l|}{ BMI by categories $\left(\mathrm{kg} / \mathrm{m}^{2}\right)$} \\
\hline normal weight & $21.6 \pm 2.2$ & $21.3 \pm 2.2$ & $22.9 \pm 1.7$ & $<0.0001$ \\
\hline overweight & $27.0 \pm 1.3$ & $26.9 \pm 1.3$ & $27.3 \pm 1.4$ & 0.01 \\
\hline obesity & $33.4 \pm 2.6$ & $32.4 \pm 2.5$ & $33.7 \pm 2.6$ & 0.06 \\
\hline \multicolumn{5}{|l|}{ BMI categories (\%) } \\
\hline normal weight & $481(60.4)$ & $410(72.6)$ & $71(30.6)$ & \\
\hline Overweight & $231(29.0)$ & $136(24.1)$ & $95(40.9)$ & $<0.0001$ \\
\hline Obesity & $84(10.5)$ & $18(3.2)$ & $66(28.4)$ & \\
\hline WHR & $0.84 \pm 0.09$ & $0.82 \pm 0.09$ & $0.90 \pm 0.08$ & $<0.0001$ \\
\hline WHR men & $0.89 \pm 0.08$ & $0.87 \pm 0.08$ & $0.91 \pm 0.07$ & $<0.0001$ \\
\hline WHR women & $0.78 \pm 0.07$ & $0.78 \pm 0.07$ & $0.83 \pm 0.07$ & $<0.0001$ \\
\hline Waist circumference men & $88.4 \pm 9.0$ & $85.1 \pm 9.0$ & $92.9 \pm 11.6$ & $<0.0001$ \\
\hline Waist circumference women & $74.2 \pm 11.3$ & $72.2 \pm 9.0$ & $89.3 \pm 14.8$ & $<0.0001$ \\
\hline \multicolumn{5}{|l|}{ Metabolic health } \\
\hline $\mathrm{SBP}(\mathrm{mmHg})$ & $126.7 \pm 14.3$ & $122.8 \pm 12.8$ & $135.6 \pm 13.7$ & $<0.0001$ \\
\hline $\mathrm{DBP}(\mathrm{mmHg})$ & $78.6 \pm 10.8$ & $76.4 \pm 9.8$ & $83.8 \pm 11.2$ & $<0.0001$ \\
\hline Total cholesterol (mmol/l) & $4.94 \pm 1.04$ & $4.65 \pm 0.9$ & $5.66 \pm 1.13$ & $<0.0001$ \\
\hline LDL-cholesterol (mmol/l) & $2.96 \pm 0.9$ & $2.67 \pm 0.8$ & $3.68 \pm 0.9$ & $<0.0001$ \\
\hline HDL-cholesterol (mmol/l) & $1.59 \pm 0.45$ & $1.70 \pm 0.41$ & $1.32 \pm 0.40$ & $<0.0001$ \\
\hline Triglycerides (mmol/l) & $1.20 \pm 1.14$ & $0.87 \pm 0.37$ & $1.99 \pm 1.80$ & $<0.0001$ \\
\hline Glucose $(\mathrm{mmol} / \mathrm{l})$ & $5.00 \pm 0.46$ & $4.89 \pm 0.38$ & $5.27 \pm 0.53$ & $<0.0001$ \\
\hline \multicolumn{5}{|l|}{ Metabolic abnormalities (\%) } \\
\hline Elevated SBP & $305(39.9)$ & $142(26.5)$ & $163(71.2)$ & $<0.0001$ \\
\hline Elevated DBP & $213(27.9)$ & $99(18.5)$ & $114(49.8)$ & $<0.0001$ \\
\hline Elevated total cholesterol & $279(35.0)$ & $121(21.4)$ & $158(68.1)$ & $<0.0001$ \\
\hline Elevated LDL-cholesterol & $237(29.7)$ & $90(15.9)$ & $147(63.4)$ & $<0.0001$ \\
\hline Lowered HDL-cholesterol & $62(7.8)$ & $8(1.4 \%)$ & $54(23.3)$ & $<0.0001$ \\
\hline Elevated triglycerides & $125(15.7)$ & $16(2.8)$ & $109(47.0)$ & $<0.0001$ \\
\hline Elevated glucose & 99 (12.4) & $21(3.7)$ & $78(33.6)$ & $<0.0001$ \\
\hline
\end{tabular}

1.16) and nutrition knowledge score (0.93 per 1 point increase, 0.9-0.97). Whereas there is a reverse dependence of MS to adherence to pHDI ( 0.39 per $10 \%$ points increase, 0.17-0.85) (Fig. 2).

In the multivariate model which included PCA-driven DPs, individuals who showed higher adherence to the "Western" DP (highest vs. lowest adherence: 1.64, 1.022.64; moderate vs. lowest adherence: $1.64,1.02-2.64$, respectively) were more likely to have MS, independently of other significant factors: male gender $(2.75,1.69-$ 4.54), BMI (1.27 per $1 \mathrm{~kg} / \mathrm{m} 2$ increase, $1.20-1.34)$, WHR (1.22 per 0.1 unit increase, $0.92-1.61)$ and age (1.06 per 1 year increase, 1.01-1.11) (Fig. 3).
In the multivariate model which included diet quality scores, MS was associated with higher adherence to nHDI (2.13 per $10 \%$ points increase, 0.89-5.12), independently of other significant factors: male gender $(2.72$, 1.67-4.49), BMI (1.27 per $1 \mathrm{~kg} / \mathrm{m} 2$ increase, $1.20-1.34)$, age (1.05 per 1 year increase, 1.01-1.10) (Fig. 4).

\section{Discussion}

In this study, adherence to the western dietary pattern and low diet quality were independent predictors of poor metabolic health.

Excessive body weight is considered a key modifiable risk factor associated with metabolic health and is 
Table 3 PCA-driven dietary patterns (DPs) identified in the total sample by principal component analysis: data from FFQ-6 questionnaire

\begin{tabular}{|c|c|c|c|}
\hline \multirow[t]{2}{*}{ Food items } & \multicolumn{3}{|c|}{ Factor loadings } \\
\hline & $\begin{array}{l}\text { Western } \\
\text { DP }\end{array}$ & $\begin{array}{l}\text { Prudent } \\
\text { DP }\end{array}$ & $\begin{array}{l}\text { Dairy, breakfast } \\
\text { cereals \& treats DP }\end{array}$ \\
\hline Processed meats & 0.70 & & \\
\hline Potatoes & 0.62 & & \\
\hline Refined grain products & 0.56 & & \\
\hline Animal fats & 0.54 & & \\
\hline Red meats & 0.53 & & \\
\hline Other edible fats & 0.45 & & \\
\hline $\begin{array}{l}\text { Sweetened beverages and } \\
\text { energy drinks }\end{array}$ & 0.40 & & \\
\hline Sugar & 0.39 & & \\
\hline Cheeses & 0.35 & & \\
\hline Vegetables & & 0.62 & \\
\hline Whole grain products & & 0.64 & \\
\hline Fish & & 0.53 & \\
\hline Eggs and egg dishes & & 0.52 & \\
\hline Nuts and seeds & & 0.52 & \\
\hline Fruit & & 0.51 & 0.43 \\
\hline Vegetable oils & & 0.41 & \\
\hline White meat & 0.30 & 0.39 & \\
\hline Legumes & & 0.38 & \\
\hline Sweetened milk products & & & 0.70 \\
\hline $\begin{array}{l}\text { Milk, fermented milk drinks } \\
\text { and curd cheese }\end{array}$ & & 0.44 & 0.54 \\
\hline Breakfast cereals & & & 0.49 \\
\hline Sweets and snacks & 0.35 & & 0.47 \\
\hline Alcohol & 0.36 & & \\
\hline Variance explained (\%) & 11.8 & 11.2 & 7.0 \\
\hline
\end{tabular}

Factor loadings of $>0.30 \mid$ are shown in the table, therefore three dietary items (out of 26) are not presented for simplicity. Sorted by loadings from 1st to 3rd factor. Total variance in dietary variables explained by three patterns is $30.0 \%$

recognized as a vital component of metabolic syndrome diagnosis in clinical practice [1]. As anticipated, depending on the model, BMI alone or both adiposity measures (BMI and WHR) were independent factors of metabolic syndrome. However, the results of our study also revealed that within the group of young people with MS, approx. $31 \%$ had BMI within a healthy range. This concurs well with previous findings. Wildman et al. [36] found, that in a Canadian cohort, nearly $25 \%$ of normal weight adults $>20$ years old were metabolically abnormal. Perceiving optimal BMI as a sole metabolic health status indicator is therefore misleading and should be complemented with additional measures by health professionals, as metabolic syndrome might occur in 20$30 \%$ of young lean adults.
Obesity is the most visible feature but can be misinterpreted as a key criterion for metabolic syndrome. It is well established that the assessment of fat distribution is more crucial than total adiposity in metabolic health screening [37]. One of the measures to define the location of excessive adipose tissue is WHR [38]. This measure has shown to be an independent predictor of metabolic health in multivariate models in our study (Figs. 3 and 4). We think, that WHR is a good diagnostic indicator of central obesity but may not be a prognostic indicator of the MS in lean patients. Based on these findings, it can be concluded that in adults with metabolic abnormalities, not only body weight management, but more specific lifestyle modifications are required. Precisely, an emphasis on diet quality might be an equally important approach in metabolic health management, which should not be neglected by clinicians. While weight loss recommendation applies to overweight patients, promoting healthy dietary patterns addresses the needs of all individuals at risks, including those with normal weight [39].

We showed that an unhealthy diet is one of the critical independent predictors of metabolic abnormalities, which was confirmed with two approaches: dietary patterns analysis and as pre-defined diet quality measure, expressed as diet quality scores. Adults with metabolic abnormalities (including 31\% those with normal BMI) were more likely to adhere to the "Western" dietary pattern and have a poor diet quality than metabolically healthy adults. The adherence to this pattern was be observed not only among obese, but also lean individuals. This observation supports previous reports, that the diet composition regardless of energy load, can play a significant role in increasing metabolic risk [14-17, 40]. A diet high in processed food, red meat, sugary snacks and low in fruit and vegetable, fish, and dairy was previously shown to be associated with an increased risk of metabolic syndrome [40]. Bahadoran et al. [14] found that fast-food intake was associated with increased risk of metabolic syndrome, which remained significant in the model adjusted for total energy intake and energy density, as well as several other potential confounders, such as sex, age, BMI, education, smoking, physical activity, total fibre, dietary intake of whole grains, fruits, vegetables, dairy, total meat, phytochemical index, and dietary total antioxidant capacity [14]. Interestingly, the association was the strongest in adults $<30$ years old. It has been suggested, that the excessive consumption of saturated- and trans-fatty acids, sugar, salt and insufficient intake of fibre, micro/macronutrient and antioxidants can trigger pathogenic mechanisms, without affecting adiposity status [14, 17]. This effect might be somewhat masked in lean individuals, who maintain healthy daily energy balance, and as a result, do not gain weight. The importance of the 'type of calories' 
Table 4 Diet quality scores (in times/day) identified in the total sample with pro-Healthy-Diet-Index (pHDI) and non-Healthy-DietIndex (nHDI) by metabolic health status: data from KomPAN questionnaire (median and interquartile range)

\begin{tabular}{|c|c|c|c|c|}
\hline Diet quality scores and food items & Total sample & $\mathrm{MH}$ & MS & $P$ value \\
\hline $\mathrm{pHDI}$ & $3.88(2.7-5.32)$ & $3.98[2.85-5.49]$ & $3.47(2.48-4.82)$ & 0.005 \\
\hline \multicolumn{5}{|l|}{ Components of pHDI } \\
\hline (1) Fruit & $0.50(0.50-1.00)$ & $0.50(0.50-1.00)$ & $0.50(0.50-1.00)$ & 0.059 \\
\hline (2) Vegetables & $0.50(0.50-1.00)$ & $0.50(0.50-1.00)$ & $0.50(0.50-1.00)$ & 0.083 \\
\hline (3) Milk & $0.50(0.14-1.00)$ & $0.50(0.14-1.00)$ & $0.50(0.06-1.00)$ & 0.031 \\
\hline (4) White meat & $0.50(0.14-0.50)$ & $0.50(0.14-0.50)$ & $0.50(0.14-0.50)$ & 0.522 \\
\hline (5) Coarse-ground groats & $0.14(0.06-0.50)$ & $0.14(0.06-0.50)$ & $0.06(0.06-0.14)$ & 0.003 \\
\hline (6) Fermented milk drinks & $0.14(0.06-0.50)$ & $0.14(0.06-0.50)$ & $0.14(0.06-0.50)$ & 0.466 \\
\hline (7) Cheese curd products & $0.14(0.06-0.50)$ & $0.14(0.06-0.50)$ & $0.14(0.06-0.50)$ & 0.598 \\
\hline (8) Whole meal bread & $0.14(0.06-0.50)$ & $0.14(0.06-0.50)$ & $0.14(0.06-0.50)$ & 0.883 \\
\hline (9) Fish & $0.06(0.06-0.14)$ & $0.06(0.06-1.00)$ & $0.06(0.06-0.14)$ & 0.989 \\
\hline (10) Legumes-based foods & $0.06(0.06-0.06)$ & $0.06(0.06-0.06)$ & $0.06(0.06-0.06)$ & 0.118 \\
\hline $\mathrm{nHDI}$ & $4.70(3.26-6.26)$ & $4.48(3.08-6.08)$ & $5.38(3.65-6.63)$ & $<0.0001$ \\
\hline \multicolumn{5}{|l|}{ Components of $\mathrm{nHDI}$} \\
\hline (1) White bread & $0.50(0.50-1.00)$ & $0.50(0.50-1.00)$ & $0.50(0.50-2.00)$ & 0.171 \\
\hline (2) Cheese & $0.50(0.14-0.50)$ & $0.50(0.14-0.50)$ & $0.50(0.14-0.50)$ & 0.035 \\
\hline (3) Cured meat & $0.50(0.14-0.75)$ & $0.50(0.14-0.50)$ & $0.50(0.50-1.00)$ & 0.002 \\
\hline (4) Fried foods & $0.50(0.14-0.50)$ & $0.50(0.14-0.50)$ & $0.50(0.14-0.50)$ & 0.025 \\
\hline (5) Sweets & $0.50(0.14-0.50)$ & $0.50(0.14-0.50)$ & $0.50(0.14-0.50)$ & 0.359 \\
\hline (6) Butter & $0.50(0.06-1.00)$ & $0.50(0.06-1.00)$ & $0.50(0.14-1.00)$ & 0.032 \\
\hline (7) Red meat & $0.14(0.06-0.50)$ & $0.14(0.06-0.50)$ & $0.14(0.06-0.50)$ & 0.039 \\
\hline (8) White rice and fine-ground groats & $0.14(0.06-0.50)$ & $0.14(0.06-0.50)$ & $0.14(0.06-0.50)$ & 0.897 \\
\hline (9) Sweetened carbonated or still drinks drinks & $0.06(0.06-0.50)$ & $0.06(0.06-0.50)$ & $0.14(0.06-0.50)$ & $<0.0001$ \\
\hline (10) Alcoholic beverages & $0.06(0.06-0.14)$ & $0.06(0.06-0.14)$ & $0.14(0.06-0.50)$ & $<0.0001$ \\
\hline (11) Fast foods & $0.06(0.06-0.14)$ & $0.06(0.06-0.14)$ & $0.06(0.06-0.14)$ & 0.010 \\
\hline (12) Energy drinks & $0.00(0.00-0.06)$ & $0.00(0.00-0.06)$ & $0.00(0.00-0.06)$ & 0.0002 \\
\hline (13) Lard & $0.00(0.00-0.06)$ & $0.00(0.00-0.06)$ & $0.00(0.00-0.06)$ & 0.011 \\
\hline (14) Tinned (jar) meats & $0.00(0.00-0.06)$ & $0.00(0.00-0.06)$ & $0.00(0.00-0.06)$ & 0.002 \\
\hline
\end{tabular}

has been previously stressed by Ludwig [15], who suggested that iso-caloric diets may trigger different responses (e.g. hormonal, gene expression) depending on the diet composition. This field of research however still require more investigation [41-43].

It is well established that positive energy balance is the main cause of obesity, however recent hypothesis announced by Stanhope et al. [44] raise the aspect that various dietary components or patterns may promote obesity and cardiometabolic diseases due to other mechanisms than increased energy intake. Some evidence suggests that high-sugar foods (closely related to the Western diet) stimulate the reward system located in the central nervous system leading to secondary overeating $[45,46]$. It has also been shown that sweetened beverages, especially fructose or sucrose-sweetened, increase the risk of developing cardiometabolic diseases and type 2 diabetes [44, 47-50]. In our study sweetened drinks were components of both "Western" dietary pattern and nHDI and its consumption was significantly more frequent in MS than $\mathrm{MH}$ subjects (data not shown). Although the mechanisms are still not fully understood, one of the potential explanation might be that non-nutritive sweeteners such as aspartame, sucralose, saccharin, acesulfame $\mathrm{K}$ and steviol glycosides indirectly affect energy balance [51-53]. The mechanism that may explain these association is the disturbance of sweet taste receptor activation and the expected relationship between sweetness and calories on gut microbiota [54-56]. The results of studies indicate that energy intake and changes alternate along with the gut microbiome composition [57-59].

The non-modifiable factors independently associated with the occurrence of metabolic abnormalities were 


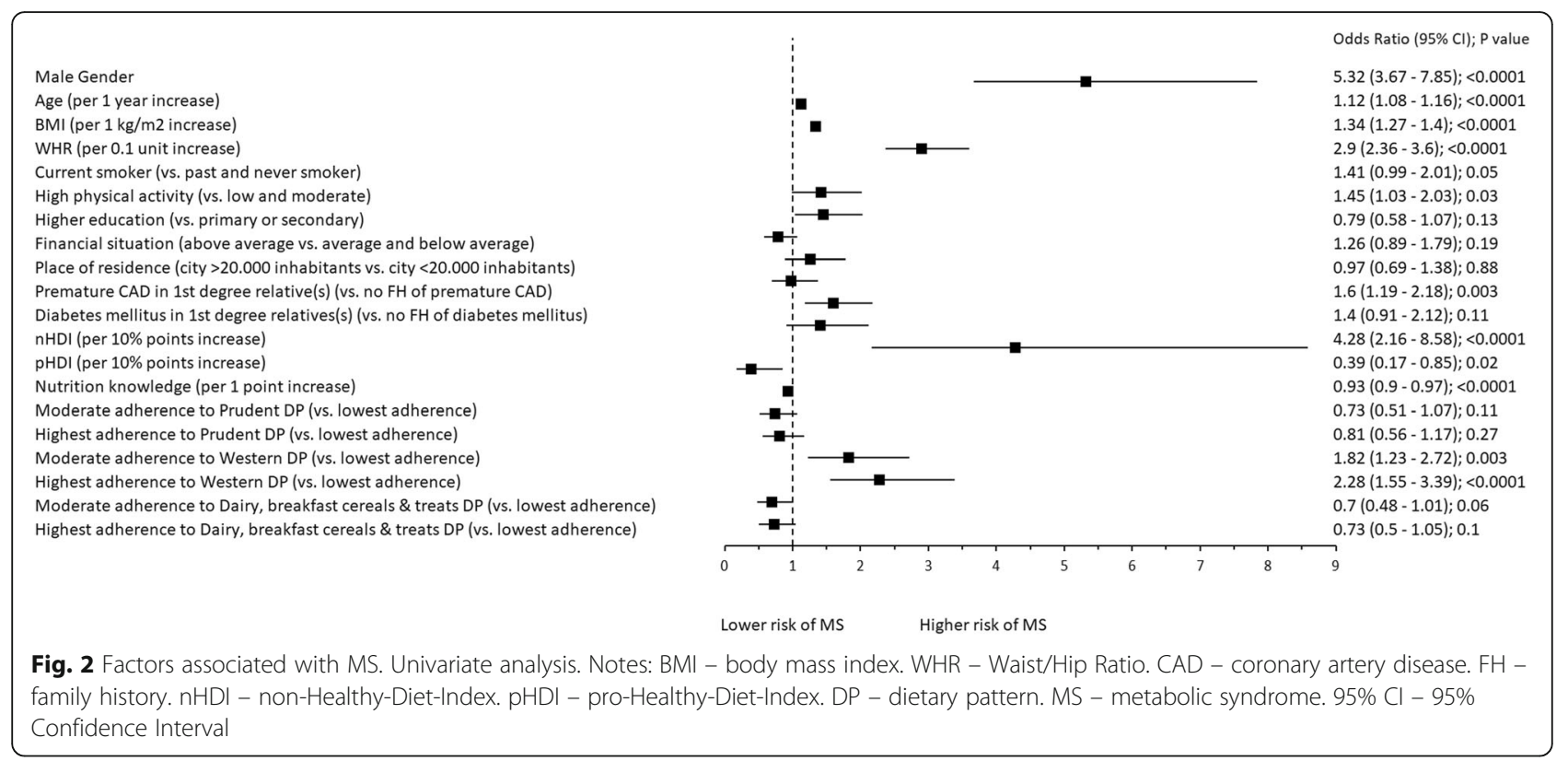

male gender and age. Men were at higher risk, which can be a result of sex-related metabolic and hormonal differences, as well as psychological and lifestyle differences [60-62]. This result is in line with previous findings from the Baltic region. Mattson et al. [63] found that in Finish adults aged 24-39 the prevalence increased with age in both sexes, but more dramatically in men. In general, women tend to make more conscious dietary choices, e.g. more frequently eat fruit and vegetables, and less likely to opt for foods high in fat [64]. The potential explanation includes genetic susceptibility or lifestyle factors; often, unhealthy lifestyle habits acquired at family home, track to adulthood [26]. An interesting finding was, that in the univariate model, high level of leisure time physical activity was associated with higher risk of MS (Fig. 2). The potential explanation is, that the diagnosis was a trigger of a spontaneous positive lifestyle change, such as increasing the level of physical activity [65]. However, this association was of marginal significance $(p=0.03)$ and it was not retained in the multivariate model. Similarly, it was not significant when the percentage distribution between the two groups was compared (Table 2).

The main strength of this study is the use of two approaches in examining diet quality - PCA-driven approach and diet quality scores [28]. Perhaps, PCA-driven approach reflected more precisely the complex matrix of diet components, with a more detrimental effect on health, than the investigator-driven approach. To our knowledge, this is the first study, which investigated the associations between diet composition and metabolic health in young adults, regardless of their adiposity status. Because of case-control study design and its intrinsic limitations, a causal relationship could not be determined so prospective studies are needed to confirm the relationship and examine underlying mechanisms associated with poor dietary choices. Paradoxically, limitation of this study is also lack of widely accepted definition of MetS in normal weight patients, therefore definition used in this study may differ from future studies. Nonetheless results of our paper add another brick to discussion of metabolic abnormalities in lean patients, while

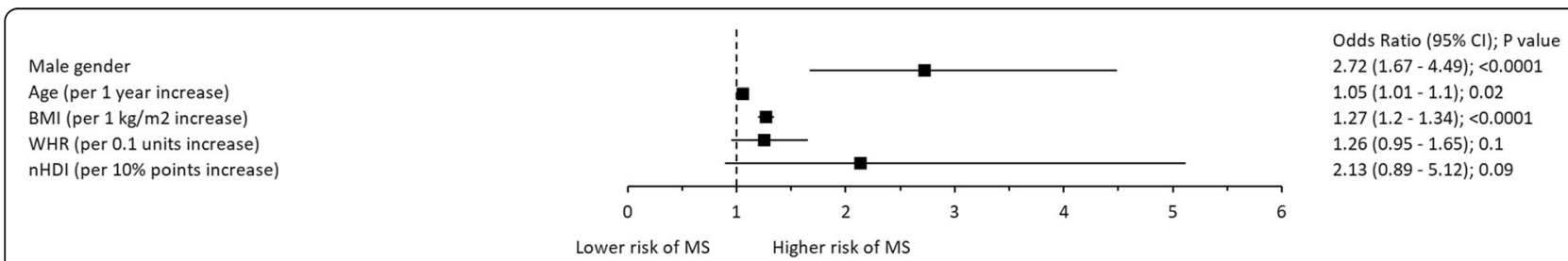

Fig. 3 Independent factors associated with MS. Multivariate analysis with the inclusion of PCA-derived dietary patterns. Variable selection was based on Akaike information criterion. Notes: BMI - body mass index. WHR - Waist/Hip Ratio. DP - dietary pattern. MS - metabolic syndrome. $95 \% \mathrm{Cl}-95 \%$ Confidence Interval 

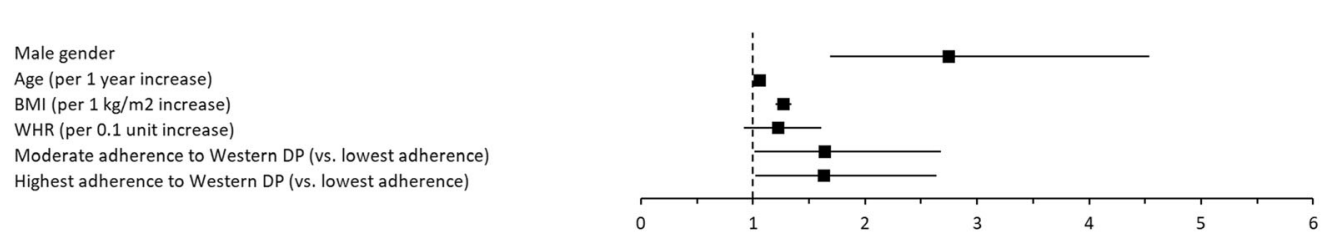

Odds Ratio ( $95 \% \mathrm{Cl})$; P value

$2.75(1.69-4.54) ;<0.0001$ $1.06(1.01-1.11) ; 0.01$ $1.27(1.2-1.34) ;<0.0001$ $1.22(0.92-1.61) ; 0.15$ $1.64(1.01-2.68) ; 0.05$ $1.64(1.02-2.64) ; 0.04$

Lower risk of MS Higher risk of MS

Fig. 4 Independent factors associated with MS. Multivariate analysis with the inclusion of pro-Healthy-Diet-Index (pHDI) and non-Healthy-DietIndex (nHDI). Variable selection was based on Akaike information criterion. Notes: BMI - body mass index. WHR - Waist/Hip Ratio. MS - metabolic syndrome. $95 \% \mathrm{Cl}-95 \%$ Confidence Interval

definition of lean MetS is still being coined. Lastly, it can be argued that a more precise assessment of abdominal obesity could have been used, such as measurement of visceral fat tissue (VAT), e.g. using magnetic resonance imaging (MRI) or computed tomography (CT) scan dual energy $\mathrm{x}$-ray absorptiometry (DEXA). Some studies suggested, that VAT has a stronger association with an unfavourable metabolic risk profile, which may not be detected with simple measurements [66]. In our study we have used simple, inexpensive anthropometric measurement, most commonly used in the clinical setting, such as BMI, WC and WHR. Interestingly, in the multivariable analysis there was association between WHR and metabolic health, whilst WC was left out of the multivariable model due to lack of statistical significance. Most probably, the reason for this was purely mathematical - although both WHR and WC alone are key indices of fat distribution, the WHR to some extent naturally corrects for sex as it includes hip circumference that is also a sex-dependent factor $[67,68]$. Therefore, WHR in the context of multivariable analysis adds more information to the model than $\mathrm{WC}$ alone.

\section{Conclusions}

Individuals with metabolic syndrome were more likely to adhere to the western dietary pattern and have a poor diet quality in comparison to metabolically healthy peers, independently of BMI and WHR. It implies that diet composition, independently, plays a pivotal role in increasing metabolic risk. Currently, in clinical practice mainly overweight or obese individuals are offered professional dietary advice, presuming that lean individuals do not require dietary modification. This may be detrimental for the latter group, in which the continuation of an unhealthy diet may escalate the abnormalities in the long-term perspective. Therefore, dietary advice should be offered to all metabolically unhealthy patients, regardless of their body mass status, with more focus on dietary quality than reducing the energy load. Remarkably, we found that the protective effect of a healthy diet was not as strong in comparison to the detrimental effect of an unhealthy diet. Perhaps, eliminating unhealthy dietary habits, rather than enforcing the healthy guidelines could be a more effective strategy in reducing the health risks.

\section{Supplementary information}

Supplementary information accompanies this paper at https://doi.org/10. 1186/s12937-020-00532-0.

Additional file 1: Table S1. Food frequency questionnaire food and food groups included in PCA-driven dietary patterns analysis (FFQ-6).

Table S2. Food frequency questionnaire food and food groups included in diet quality scores analysis (KomPAN questionnaire). Table S3. Missing data.

Additional file 2. Dataset (raw data): Study dataset.

Additional file 3. Dataset (imputed data): Dataset with imputed values using random forest algorithm (used for multivariable analysis).

\section{Abbreviations}

BMI: Body mass index; CAD: Coronary artery disease; DBP: Diastolic blood pressure; DPs: Dietary patterns; FFQ-6: Food frequency questionnaire with 6 answers; HDL: High-density cholesterol; IQR: Interquartile range; KomPAN: Dietary Habits and Nutrition Beliefs Questionnaire;

MAGNETIC: Metabolic and Genetic Profiling of Young Adults with and without a Family History of Premature Coronary Heart Disease Study; $\mathrm{MH}$ : Metabolically healthy subjects; missForest: Non-parametric missing value imputation for mixed-type data; MS: Metabolic syndrome; nHDI: NonHealthy-Diet-Index; PCA: Principal component analysis; P-CAD: Premature coronary artery disease; pHDI: Pro-Healthy-Diet-Index; SDs: Standard deviations; VAT: Visceral adipose tissue; WHO: World Health Organization; WHR: Waist-hip ratio

\section{Acknowledgements}

We would like to thank nurses from Silesian Centre for Heart Diseases for help in patient's recruitment and laboratory personnel for performing necessary laboratory measurements.

\section{Authors' contributions}

$\mathrm{TO}, \mathrm{NP}, \mathrm{KO}$, and MG made substantial contributions to the design of the study. TO, NP, KO, MF, RR, and MG were involved in the data acquisition. TO and $L W$ analyzed and contributed to the interpretation of the data. TO, ML, $M L$, and LW, interpreted the data and wrote the manuscript. All authors were involved in critically revising the manuscript, and have given their approval to the manuscript submitted.

\section{Funding}

The study is financed by the National Science Centre (2014/13/B/NZ5/03166, OPUS 7).

\section{Availability of data and materials}

All data generated or analysed during this study are included in this published article [see Additional file 2. Dataset (raw data), Additional file 3. Dataset (imputed data)]. 


\section{Ethics approval and consent to participate}

The study was conducted following the Declaration of Helsinki and good clinical practice. The study protocol has been approved by the Ethics Committee at Institute of Occupational Medicine and Environmental Health, Sosnowiec and Medical University of Silesia. Informed written consent was obtained from all subjects enrolled to the study.

\section{Consent for publication}

Not applicable.

\section{Competing interests}

The authors declare that they have no competing interests. The founding sponsors had no role in the design of the study; in the collection, analyses, or interpretation of data; in the writing of the manuscript, and in the decision to publish the results.

\section{Author details}

${ }^{1}$ Department of Pharmacology, Faculty of Medical Sciences in Zabrze, Medical University of Silesia, Jordana 38, 41-808 Zabrze, Poland. ${ }^{2}$ 2nd Department of Cardiology and Angiology, Silesian Center for Heart Diseases, Marii Skłodowskiej-Curie 9, 41-800 Zabrze, Poland. ${ }^{3}$ Department of Human Nutrition, Faculty of Food Science, University of Warmia and Mazury in Olsztyn, Słoneczna 45f, 10-718 Olsztyn, Poland. ${ }^{4} 3$ rd Department of Cardiology, Faculty of Medical Sciences in Zabrze, Medical University of Silesia, Marii Skłodowskiej-Curie 9, 41-800 Zabrze, Poland. ${ }^{5}$ Department of Medical and Molecular Biology, Faculty of Medical Sciences in Zabrze, Medical University of Silesia, Jordana 19, 41-808 Zabrze, Poland. ${ }^{6}$ Department of Environmental Medicine and Epidemiology, Faculty of Medical Sciences in Zabrze, Medical University of Silesia, Jordana 19, 41-808 Zabrze, Poland.

\section{Received: 16 July 2019 Accepted: 11 February 2020}

Published online: 25 February 2020

\section{References}

1. The IDF consensus worldwide definition of the metabolic syndrome. 2006. https://www.idf.org/e-library/consensus-statements/60-idfconsensusworldwide-definitionof-the-metabolic-syndrome. Accessed 23 Mar 2019.

2. Buscemi S, Chiarello P, Buscemi C, Corleo D, et al. Characterization of metabolically healthy obese people and metabolically unhealthy normalweight people in a general population cohort of the ABCD study. J Diabetes Res. 2017. https://doi.org/10.1155/2017/9294038.

3. Ruderman NB, Schneider SH, Berchtold P. The "metabolically-obese", normal-weight individual. Am J Clin Nutr. 1981;34(8):1617-21.

4. Sanyal D. Lean metabolic syndrome: an emerging concept. Indian J Endocrinol Metab. 2018. https://doi.org/10.4103/2230-8210.236782.

5. Cefalu WT, Bray GA, Home PD, et al. Advances in the science, treatment, and prevention of the disease of obesity: reflections from a diabetes care editors' expert forum. Diabetes Care. 2015. https://doi.org/ 10.2337/dc15-1081.

6. De Lorenzo A, Martinoli R, Vaia F, et al. Normal weight obese (NWO) women: an evaluation of a candidate new syndrome. Nutr Metab Cardiovas. 2006;16(8):513-23.

7. Geetha L, Deepa M, Anjana RM, Mohan V. Prevalence and clinical profile of metabolic obesity and phenotypic obesity in Asian Indians. JDST. 2011:5(2):439-46.

8. Thomas EL, Parkinson JR, Frost GS, Goldstone AP, Doré CJ, McCarthy JP, et al. The missing risk: MRI and MRS phenotyping of abdominal adiposity and ectopic fat. Obesity. 2012;20(1):76-87.

9. Aung K, Lorenzo C, Hinojosa MA, Haffner SM. Risk of developing diabetes and cardiovascular disease in metabolically unhealthy normalweight and metabolically healthy obese individuals. J Clin Endocr Metab. 2014;99(2):462-8.

10. Engin A. The definition and prevalence of obesity and metabolic syndrome. Adv Exp Med Biol. 2017. https://doi.org/10.1007/978-3-319-48382-5_1.

11. Sarkar S, Paul BK, Chakraborty PK, Akhter S, Hossain MM, Hoque MR, Yesmin M. Association between metabolic syndrome and acute myocardial infarction (AMI). Mymensingh Med J. 2016;25(4):628-34 PMID: 27941721.

12. Li X, Li X, Lin H, Fu X, Lin W, Li M, Gao Q. Metabolic syndrome and stroke: a meta-analysis of prospective cohort studies. J Clin Neurosci. 2017:40:34-8.

13. Hamer M, Stamatakis E. Metabolically healthy obesity and risk of all-cause and cardiovascular disease mortality. J Clin Endocrinol Metab. 2012;97(7):2482-8.
14. Bahadoran Z, Mirmiran P, Hosseini-Esfahani F, et al. Fast food consumption and the risk of metabolic syndrome after 3-years of follow-up: Tehran lipid and glucose study. Eur J Clin Nutr. 2013;67:1303-9. https://doi.org/10.1038/ ejcn.2013.217.

15. Ludwig DS. Lifespan weighed down by diet. JAMA. 2016;315(21):2269-70.

16. Grundy SM, Abate N, Chandalia M. Diet composition and the metabolic syndrome: what is the optimal fat intake? Am J Med. 2002;113(9):25-9. https://doi.org/10.1016/s0002-9343(01)00988-3.

17. Lustig RH. Metabolic syndrome and the 'Western diet': science and politics; in: Kiess W, Wabitsch M, Maffeis C, Sharma AM (eds): Metabolic syndrome and obesity in childhood and adolescence. Pediatr Adolesc Med. 2015;19: 137-47. https://doi.org/10.1159/000368125.

18. GBD 2015 Risk Factors Collaborators. Global, regional, and national comparative risk assessment of 79 behavioural, environmental and occupational, and metabolic risks or clusters of risks, 1990-2015: a systematic analysis for the Global Burden of Disease Study 2015. Lancet. 2016:388(10053):1659-724.

19. Michels KB, Schulze MB. Can dietary patterns help us detect diet-disease associations? Nutr Res Rev. 2005. https://doi.org/10.1079/NRR2005107.

20. Lutsey PL, Steffen LM, Stevens J. Dietary intake and the development of the metabolic syndrome. The atherosclerosis risk in communities study. Circulation. 2008;117:754-61.

21. Deshmukh-Taskar PR, O'Neil CE, Nicklas TA, Yang SJ, Liu Y, Gustat J, Berenson GS. Dietary patterns associated with metabolic syndrome, sociodemographic and lifestyle factors in young adults: the Bogalusa heart study. Public Health Nutr. 2009;12(12):2493-503.

22. Suliga E, Kozieł D, Cieśla E, Rębak D, Głuszek S. Dietary patterns in relation to metabolic syndrome among adults in Poland: a cross-sectional study. Nutrients. 2017. https://doi.org/10.3390/nu9121366.

23. Rodríquez-Monforte M, Sánchez E, Barrio F, Costa B, Flores-Mateo G. Metabolic syndrome and dietary patterns: a systematic review and metaanalysis of observational studies. Eur J Nutr. 2017;56(3):925-47.

24. Shab-Bidar S, Golzarand M, Hajimohammadi M, Mansouri S. A posteriori dietary patterns and metabolic syndrome in adults: a systematic review and meta-analysis of observational studies. Public Health Nutr. 2018. https://doi. org/10.1017/\$1368980018000216.

25. Osadnik T, Osadnik K, Pawlas N, Strzelczyk JK, Kasperczyk J, Poloński L, Gąsior M. Metabolic and genetic profiling of young adults with and without family history of premature coronary artery disease (MAGNETIC). Study design and methodology. Arch Med Sci. 2018. https://doi.org/10.5114/aoms.2018.75895.

26. Osadnik T, Pawlas N, Lonnie M, et al. Family history of premature coronary artery disease (P-CAD)-a non-modifiable risk factor? Dietary patterns of young healthy offspring of P-CAD patients: a case-control study (MAGNETIC project). Nutrients. 2018. https://doi.org/10.3390/nu10101488.

27. WHO. Physical status: the use and interpretation of anthropometry: report of a World Health Organization (WHO) Expert Committee. Geneva: World Health Organization; 1995.

28. Kant AK. Dietary patterns: biomarkers and chronic disease risk. Appl Physiol Nutr Metab. 2019;35:199-206 https://doi.org/10.1139/H10-005.

29. Niedzwiedzka E, Wadolowska L, Kowalkowska J. Reproducibility of a nonquantitative food frequency questionnaire (62-item FFQ-6) and PCA-driven dietary pattern identification in 13-21-year-old females. Nutrients. 2019;11:2183.

30. Drabińska N, Jarocka-Cyrta E, Markiewicz L, Krupa-Kozak U. The effect of oligofructose-enriched inulin on faecal bacterial counts and microbiotaassociated characteristics in celiac disease children following a gluten-free diet: results of a randomized, placebo-controlled trial. Nutrients. 2018. https://doi.org/10.3390/nu10020201.

31. Stachowska E, Ryterska K, Maciejewska D, Banaszczak M, Milkiewicz P, Milkiewicz M, Raszeja-Wyszomirska J, et al. Nutritional strategies for the individualized treatment of non-alcoholic fatty liver disease (NAFLD) based on the nutrient-induced insulin output ratio (NIOR). Int J Mol Sci. 2016. https://doi.org/10.3390/ijms17071192.

32. Krusinska B, Hawrysz I, Wadolowska L, Slowinska M, Biernacki M, Czerwinska A, Golota JJ. Associations of Mediterranean diet and a posteriori derived dietary patterns with breast and lung cancer risk: a case-control study. Nutrients. 2018. https://doi.org/10.3390/nu10040470.

33. Jezewska-Zychowicz M, Gawecki J, Wadolowska L, Czarnocinska J, Galinski G, Kollajtis-Dolowy A, Roszkowski W, Wawrzyniak A, Przybylowicz K, Krusinska B, et al. Dietary habits and nutrition beliefs questionnaire and the manual for developing of nutritional data. The Committee of Human Nutrition, Polish Academy of Sciences. http://www.knozc.pan.pl/. ; 
34. Kowalkowska J, Wadolowska L, Czarnocinska J, Czlapka-Matyasik M, Galinski G, Jezewska-Zychowicz M, Bronkowska M, Dlugosz A, Laboda D, Wyka J. Reproducibility of a questionnaire for dietary habits, lifestyle and nutrition knowledge assessment (KomPAN) in polish adolescents and adults. Nutrients. 2018;10(12):1845-63.

35. Panagiotakos DB, Pitsavos C, Skoumas Y, Stefanadis $C$. The association between food patterns and the metabolic syndrome using principal components analysis: the ATTICA study. J Am Diet Assoc. 2007;107(6):979-87.

36. Wildman RP, Muntner P, Reynolds K, McGinn AP, Rajpathak S, Wylie-Rosett J, et al. The obese without cardiometabolic risk factor clustering and the normal weight with cardiometabolic risk factor clustering: prevalence and correlates of 2 phenotypes among the US population (NHANES 1999-2004). Arch Intern Med. 2008;168:1617-24.

37. Ritchie SA, Connell JMC. The link between abdominal obesity, metabolic syndrome and cardiovascular disease. Nutr Metab Cardiovasc Dis. 2008; 17(4):319-26.

38. de Koning L, Merchant AT, Pogue J, Anand SS. Waist circumference and waist-to-hip ratio as predictors of cardiovascular events: meta-regression analysis of prospective studies. Eur Heart J. 2007;28(7):850-6.

39. Fernandes AC, Rieger DK, Proença RPC. Perspective: public health nutrition policies should focus on healthy eating, not on calorie counting, even to decrease obesity. Adv Nutr. 2019. https://doi.org/10.1093/advances/nmz025.

40. Drake I, Sonestedt E, Ericson U, Wallström P, Orho-Melander M. A Western dietary pattern is prospectively associated with cardio-metabolic traits and incidence of the metabolic syndrome. Br J Nutr. 2018;119(10):1168-76.

41. Camacho S, Ruppel A. Is the calorie concept a real solution to the obesity epidemic? Glob Health Action. 2017;10(1):1289650. https://doi.org/10.1080/ 16549716.2017.1289650.

42. Sánchez I, Reynoso-Camacho R, Salgado LM. The diet-induced metabolic syndrome is accompanied by whole-genome epigenetic changes. Genes Nutr. 2015;10(4):471. https://doi.org/10.1007/s12263-015-0471-5.

43. Schüler R, Osterhoff MA, Frahnow T, et al. High-saturated-fat diet increases circulating angiotensin-converting enzyme, which is enhanced by the rs4343 polymorphism defining persons at risk of nutrient-dependent increases of blood pressure. J Am Heart Assoc. 2017;6(1):e004465. https:// doi.org/10.1161/JAHA.116.004465.

44. Stanhope KL, Goran MI, Bosy-Westphal A, King JC, Schmidt LA, Schwarz JM, Stice E, Sylvetsky AC, Turnbaugh PJ, Bray GA, Gardner CD, Havel PJ, Malik V, Mason AE, Ravussin E, Rosenbaum M, Welsh JA, Allister-Price C, Sigala DM, Greenwood MRC, Astrup A, Krauss RM. Pathways and mechanisms linking dietary components to cardiometabolic disease: thinking beyond calories. Obes Rev. 2018;19(9):1205-35.

45. Moore C, Sabino V, Koob G, et al. Pathological overeating: emerging evidence for a compulsivity construct. Neuropsychopharmacol. 2017:42: 1375-89. https://doi.org/10.1038/npp.2016.269.

46. la Fleur S, Luijendijk $M$, van der Zwaal $E$, et al. The snacking rat as model of human obesity: effects of a free-choice high-fat high-sugar diet on meal patterns. Int J Obes. 2014;38:643-9. https://doi.org/10.1038/ijo.2013.159.

47. Stice E, Yokum S, Blum K, Bohon C. Weight gain is associated with reduced striatal response to palatable food. J Neurosci. 2010;30:13105-9.

48. Stice E, Yokum S. Gain in body fat is associated with increased striatal response to palatable food cues, whereas body fatstability is associated with decreased striatal response. J Neurosci. 2016;36:6949-56.

49. Yokum S, Gearhardt AN, Harris JL, Brownell KD, Stice E. Individual differences in striatum activity to food commercials predict weight gain in adolescents. Obesity (Silver Spring). 2014;22:2544-51.

50. Stice E, Burger KS, Yokum S. Reward region responsivity predicts future weight gain and moderating effects of the TaqIA allele. J Neurosci. 2015;35: 10316-24.

51. Nettleton JA, Lutsey PL, Wang Y, Lima JA, Michos ED, Jacobs DR Jr. Diet soda intake and risk of incident metabolic syndrome and type 2 diabetes in the multi-ethnic study of atherosclerosis (MESA). Diabetes Care. 2009;32:688-94

52. Sakurai M, Nakamura K, Miura K, et al. Sugar-sweetened beverage and diet soda consumption and the 7-year risk for type 2 diabetes mellitus in middle-aged Japanese men. Eur J Nutr. 2014;53:251-8.

53. de Koning L, Malik VS, Rimm EB, Willett WC, Hu FB. Sugar-sweetened and artificially sweetened beverage consumption and risk of type 2 diabetes in men. Am J Clin Nutr. 2011:93:1321-7.

54. Pepino MY. Metabolic effects of non-nutritive sweeteners. Physiol Behav. $2015 \cdot 152 \cdot 450-5$
55. Shearer J, Swithers SE. Artificial sweeteners and metabolic dysregulation: lessons learned from agriculture and the laboratory. Rev Endocr Metab Disord. 2016;17:179-86.

56. Fowler SP. Low-calorie sweetener use and energy balance: results from experimental studies in animals, and large-scale prospective studies in humans. Physiol Behav. 2016;164:517-23.

57. Turnbaugh PJ, Backhed F, Fulton L, Gordon Jl. Diet-induced obesity is linked to marked but reversible alterations in the mouse distal gut microbiome. Cell Host Microbe. 2008;3:213-23.

58. Ridaura VK, Faith JJ, Rey FE, et al. Gut microbiota from twins discordant for obesity modulate metabolism in mice. Science. 2013. https://doi.org/10. 1126/science.1241214

59. Vrieze A, Van Nood E, Holleman F, et al. Transfer of intestinal microbiota from lean donors increases insulin sensitivity in individuals with metabolic syndrome. Gastroenterology. 2012;143:913-6 e7.

60. EUGenMed Cardiovascular Clinical Study Group, Regitz-Zagrosek V, OerteltPrigione S, Prescott E, Franconi F, Gerdts E, Foryst-Ludwig A, Maas AH, Kautzky-Willer A, Knappe-Wegner D, Kintscher U, Ladwig KH, SchenckGustafsson K, Stangl V. Gender in cardiovascular diseases: impact on clinical manifestations, management, and outcomes. Eur Heart J. 2016. https://doi. org/10.1093/eurheartj/ehv598.

61. Krieger N. Genders, sexes, and health: what are the connections - and why does it matter? Int J Epidemiol. 2003;32(4):652-7.

62. Asarian L, Geary N. Sex differences in the physiology of eating. Am J Physiol Regul Integr Comp Physiol. 2013. https://doi.org/10.1152/ ajpregu.00446.2012.

63. Mattsson N, Rönnemaa T, Juonala M, Viikari JSA, Raitakari OT. The prevalence of the metabolic syndrome in young adults. The cardiovascular risk in young Finns study. J Intern Med. 2007;261:159-69. https://doi.org/10. 1111/j.1365-2796.2006.01752.x.

64. Wardle J, Haase AM, Steptoe A, Nillapun M, Jonwutiwes K, Bellisle F. Gender differences in food choice: the contribution of health beliefs and dieting. Ann Behav Med. 2004;27(2):107-16.

65. Kostopoulou V, Katsouyanni K. The truth-telling issue and changes in lifestyle in patients with cancer. J Med Ethics. 2006;32(12):693-7. https://doi. org/10.1136/jme.2005.015487.

66. Fox CS, Massaro JM, Hoffmann U, Pou KM, Maurovich-Horvat P, et al. Abdominal visceral and subcutaneous adipose tissue compartments. Circulation. 2007;116:39-48 https://doi.org/10.1161/CIRCULATIONAHA. 106.675355.

67. Lapidus L, Bengtsson C, Larsson B, Pennert K, Rybo E, Sjöström L. Distribution of adipose tissue and risk of cardiovascular disease and death: a 12 year follow up of participants in the population study of women in Gothenburg, Sweden. Br Med J (Clin Res Ed). 1984;289(6454):1257-61. https://doi.org/10.1136/bmj.289.6454.1257.

68. World Health Organization. (2011). Waist circumference and waist-hip ratio: report of a WHO expert consultation, Geneva, 8-11 December 2008. World Health Organization. https://apps.who.int/iris/handle/10665/44583. Accessed 17 Feb 2020

\section{Publisher's Note}

Springer Nature remains neutral with regard to jurisdictional claims in published maps and institutional affiliations.

Ready to submit your research? Choose BMC and benefit from:

- fast, convenient online submission

- thorough peer review by experienced researchers in your field

- rapid publication on acceptance

- support for research data, including large and complex data types

- gold Open Access which fosters wider collaboration and increased citations

- maximum visibility for your research: over $100 \mathrm{M}$ website views per year

At $\mathrm{BMC}$, research is always in progress.

Learn more biomedcentral.com/submission 